YYÜ Eğitim Fakültesi Dergisi (YYU Journal of Education Faculty), 2019; 16(1):725-743, http://efdergi.yyu.edu.tr

\title{
Sanal Öğrenme Ortamlarındaki Öğrenci Davranışlarının Kümeleme Yöntemi İle Analiz Edilmesi \\ Meltem ERYILMAZ*
}

Öz: Öğrenme sürecini yönetmek ve öğrencilerin kendi öğrenmelerinden sorumlu olmalarını sağlamak amacına yönelik uygun araçlar sunan sanal öğrenme ortamları, bu özellikleri ile eğitimci ve öğrencilere geniş imkanlar sağlamaktadır. Tüm bu imkânlara rağmen aynı öğretim kurumu içerisinde sanal öğrenme ortamlarının yeterince etkili kullanılmadığı görülmektedir. $\mathrm{Bu}$ deneysel araştırmada sanal öğrenme ortamı olarak Moodle kullanılan bir üniversitede, kullanıcıların ortamı kullanma bilgileri veri madenciliği tekniklerinden kümeleme algoritmaları ile analiz edilerek, ortamda kullanılması tercih edilmeyen ya da daha az tercih edilen bileşenler tespit edilmiştir. Araştırmaya Ankara Atılım Üniversitesi Fen ve Edebiyat Fakültesi’nde Bilgisayara ve Bilgi Sistemlerine Giriş dersini alan 131 öğrenci katılmıştır. Uygulama sürecinde tüm öğrenciler dersi haftada bir kez yüz yüze geri kalanını Moodle sanal öğrenme ortamında olmak üzere harmanlanmış öğrenme yaklaşımı ile almışlardır. Verilerin analizinde kümeleme algoritmalarından k-ortalamalar analizi kullanılmıştır. Kümeleme analizi ile öğrencilerin sanal öğrenme ortamına yönelik memnuniyetleri, bilgisayar kaygıları ve yıl sonu akademik başarılarına göre nasıl bir dağılım gösterdikleri belirlenmiştir. Ayrıca bu dağılıma göre sanal öğrenme ortamındaki aktivite kullanımları arasında farklılık olup olmadığ 1 değerlendirilmiştir.

Anahtar Kelimeler: Sanal öğrenme ortamları, memnuniyet, kaygı, akademik başarı, k ortalamalar kümeleme analizi, eğitimsel veri madenciliğii.

\section{The Analysis of Student Behaviors in Virtual Learning Environments by Clustering Method}

Abstract: Virtual learning environments offer a wide range of opportunities for educators and students, providing the appropriate tools for managing the learning process and ensuring that

\footnotetext{
* Dr. Öğr. Üyesi, Atılım Üniversitesi, Mühendislik Fakültesi, Bilgisayar Mühendisliği Bölümü, Email:meltem.eryilmaz@atilim.edu.tr Orcid No: 0000-0001-9483-6164.

Gönderim:02.11.2018 Kabul:14.03.2019 Kayın:20.05.2019
} 
YYÜ Ĕ̆itim Fakültesi Dergisi (YYU Journal of Education Faculty), 2019; 16(1):725-743, http://efdergi.yyu.edu.tr

students are responsible for their own learning. Despite all these opportunities, even within the same educational institution, it is seen that virtual learning environments are not used effectively. In this experimental research, in Atılım University, Ankara where Moodle is used as a virtual learning environment, the use of the environment by the users is analyzed by data mining techniques using clustering algorithms, and it is determined which are preferred or less preferred components in the environment. The research was conducted on 131 students who attended the Introduction to Computers and Information Systems course at a university in Ankara. During the practicing process, the students took a face to face course per week and the rest of the course in the Moodle virtual learning environment at the same time by the blended learning approach. In the analysis of the data, it was determined how the students were distributed according to their satisfaction with the virtual learning environment, computer anxiety and academic achievement by using k-means analysis from clustering algorithms. In addition, according to this distribution, the use of activity in the virtual learning environment is evaluated whether there is a difference between them.

Keywords: Virtual learning environments, satisfaction, anxiety, academic achievement, k-means clustering analysis, educational data mining.

\section{Giriş}

Bilgi ve iletişim teknolojilerindeki hızlı gelişsim, sürekli değişim gösteren eğitim sürecini direk olarak etkileyerek ilerlemesinde önemli rol oynamaktadır. Bu etkileşim ile eğitim yepyeni bir boyut kazanarak, internet tabanlı e-öğrenme, sanal öğrenme ortamları, mobil öğrenme, harmanlanmış öğrenme, elektronik ortamlarda bilgiye erişim, eğitimde öğretim teknolojilerinin etkili kullanımı gibi konular gündeme gelmiştir. Günümüzde daha iyi ve etkili bir öğrenme için teknoloji destekli eğitim kaçınılmaz bir hale gelmiş, çevirimiçi ve yüz yüze eğitimde teknoloji entegrasyonu çalışmaları ağırlık kazanmıştır. Özellikle e-öğrenme kavramının popülaritesinin artması ile harmanlanmış öğrenme (blended learning) yaklaşımı son yıllarda oldukça önem kazanmıştır (Osguthorpe ve Graham, 2003). Araştırmalar, sanal öğrenme ortamları ile geleneksel yüz yüze öğrenme ortamlarının kuvvetli yönlerini birleştirerek uygulanan harmanlanmış öğrenmenin, öğrencilerin motivasyonlarının artışına, iletişim, etkileşim ve akademik başarılarındaki olumlu etkilerine dikkat çekmişlerdir (ElDeghaidy ve Nouby, 2008; Osguthorpe ve Graham, 2003; Garnham ve Kaleta, 2002).

Güncel teknolojilerin, öğrencilerin çevrimiçi bilgisayar kullanmaları yoluyla uzaktan eğitim almalarını sağlayan sanal öğrenme ortamlarında kullanılabilmesi, eğitim ve öğretim 
YYÜ Eğitim Fakültesi Dergisi (YYU Journal of Education Faculty), 2019; 16(1):725-743, http://efdergi.yyu.edu.tr

sürecini olumlu yönde etkileyerek öğrenen ve eğitimci açısından çok zengin ders etkinliklerinin yapılabilmesine olanak sağlamaktadır. Bu ortamlar sayesinde öğrenciler ders materyallerine her an ulaşabilmekte, diğer öğrenenlerle etkileşim halinde olabilmekte ve paylaşımlarda bulunarak işbirlikli çalışmalar yapabilmektedirler (Romero ve diğerleri, 2013). Eğitimciler ödev ve test gibi etkinlikleri çevirim içi olarak hazırlama ve uygulama imkanlarına sahiptirler. Aynı zamanda öğrencilerin sistemdeki hareketlerini izleyebilmektedirler. Sanal öğrenme ortamları, öğrenci etkinliklerini izleyebilme, kayıt tutabilme ve öğrenci aktivitesi üzerine önemli miktarda veri toplayabilme özellikleri ile geleneksel sınıf ortamından farklılık göstererek özellikle son yıllarda eğitim alanında yaygın olarak tercih edilmektedirler (Siemens ve Long, 2011). Ancak sanal öğrenme ortamlarının sunmuş olduğu bu gelişmiş imkanlara rağmen, ortamlara ait tüm bileşenlerin yeterince kullanılmadığı görülmektedir (Kışla ve diğerleri, 2014). Araştırmalar öğrencilerin sanal öğrenme ortamlarındaki etkinliklere katılımları ve aktif olarak ortamı kullanımlarının akademik performansları ile ilişkili olduğunu belirtmektedirler (Casey ve Gibson, 2010). Sanal öğrenme ortamlarında yer alan bileşenlerde oluşabilecek bir aksaklık, öğrenme sürecini olumsuz olarak etkileyebilmektedir. Bu sebeple öğrenme sürecinin etkili ve sürdürülebilir olabilmesini sağlayan faktörlerin süreç boyunca göz önünde bulundurulması, öğrenen performansını düşüren olumsuz faktörlerin ortadan kaldırılması gerekmektedir.

E-öğrenme ortamlarında yaşanan olumsuzlukların genel olarak öğrenenlerin eöğrenmeye yönelik öz yeterlik, tutum, kayg1, direnç ve motivasyon eksiklikleri ile ilgili olduğu görülmektedir (Semerci ve Keser, 2013). Murray (2001), e-öğrenme hakkındaki bilgi eksikliğinin öğrenenler üzerinde ön yarg1 ve şüphelere neden olabileceğini belirtmiştir. Bu durumda öğrenenler sanal öğrenme ortamlarındaki bileşenleri nasıl kullanacağını bilememekte, yararlarının farkında olamamakta ya da ortamları etkili kullanamamaktadırlar. Zaman yönetimindeki problemler, öğrenenlerin kendi öğrenmelerinden sorumlu olmamaları, bilgisayar ve internet kullanma becerilerindeki yetersizlikler, farklı bir öğrenme ortamına karşı duyulan kaygı, iletişim kanallarını etkin kullanamama, teknoloji korkusu, teknik altyapı, eğitimcilerin ortama hâkim olmamaları gibi konular, öğrenenler açısından sanal öğrenme ortamlarının kullanımındaki engeller olarak belirtilmektedir (Australian Flexible Learning Framework, 2007). Ortamlar ne derece başarılı tasarlanırsa tasarlansın, ortamlardaki bileşenlerin yeterince etkili bir şekilde kullanılamaması öğrenme sürecini olumsuz yönde etkileyecektir. Bu durumda öğrenenlerin sanal öğrenme ortamları kullanımında karşılaştıkları 
YYÜ Eğitim Fakültesi Dergisi (YYU Journal of Education Faculty), 2019; 16(1):725-743, http://efdergi.yyu.edu.tr

engellerin ortadan kaldırılması ve hangi bileşenlerin kullanımında problem yaşadıklarının belirlenmesi öğretim sürecinin sağlıklı bir şekilde sürdürülmesi için gereklidir. Öğrenenlerin kendi öğrenme etkinliklerini planlama ve uygulamada sorumluluk sahibi olduklarında motivasyonlarının ve başarılarının arttığg görülmektedir (Mansouri, 2003).

$\mathrm{Bu}$ araştırmada mevcut bütün avantajlarına rağmen sanal öğrenme ortamlarının öğretim kurumlarında neden yeterince etkin bir şekilde kullanılmadığı probleminden yola çıkılarak açık kaynak kodlu bir sanal öğrenme ortamı olan moodle öğrenme platformu kullanılan bir dersteki öğrencilerin, ortamı kullanırken sergiledikleri davranışlar incelenmiştir. İnceleme yapılırken veri madenciliği yöntemlerinden kümeleme yöntemi kullanılmıştır.

\section{Ĕ̆itimde Veri Madenciliği}

Moodle gibi sanal öğrenme ortamlarından gelen log verilerinin kullanılabilirliği, öğrenme çıtılarını geliştirmek ve öğrencilerin öğrenme sürecinde yaşadıkları zorlukları ele almak için bir firsat sunmaktadır (Agnihotri, 2014; Siemens ve Long, 2011). Araştırmalar, belirli etkinliklere katılımların, potansiyel olarak iyi öğrenci performansının göstergesi olduğunu göstermiştir. Sanal öğrenme ortamlarındaki yüksek aktivite seviyesinin öğrenci başarısı ile doğru orantılı olduğu görülmektedir (Casey ve Gibson, 2010). Bu durumda öğrencilerin öğrenme ortamlarında yapmış oldukları aktivitelerin düzenli bir şekilde izlenmesi önem kazanmaktadır. Ancak veri tabanlarında tutulan öğrencilere ait büyük ölçekteki verilerin raporlamadan öteye kullanılmadığı, eğitimciler tarafından tam olarak takip edilemediği ve öğrenme ve öğretme sürecinin iyileştirilmesinde yeterince yararlanılmadığı söylenilebilir. Sanal öğrenme ortamları veri tabanlarındaki bilgileri istatistiksel olarak raporlasalar da öğrenci hareketliliğine dair anlamlı bilgilerin elde edilmesini, veri örüntülerinin tanımlanmasını, görselleştirilmesini ve analizini sağlayacak gelişmiş araçlara sahip değillerdir (Talavera ve Gaudioso, 2004). Büyük ölçekteki verilerin üretilip depolandığı her alanda veri madenciliği yöntemleri uygulanabilmektedir (Erten, 2015). Bu aşamada eğitim alanında kullanılan veri madenciliği, veriye dayalı bilginin analizi konusundaki potansiyeli ile bir çözüm önerisi olarak ortaya çıkmaktadır. Eğitimsel veri madenciliği yöntemleri, öğrenci performans kestirimlerinde, destek ve geri bildirimlerinde, karar verme ve strateji oluşturmada kullanılabilmektedir (Greller ve Drachsler, 2012). Veri madenciliğinin eğitimde kullanılması gibi yeni yaklaşımlar sayesinde eğitim ortamlarından elde edilen büyük veri yığınları analiz edilebilmekte, böylelikle öğrenme süreci ve öğrenci davranışları hakkında bilgi sahibi olunabilmekte benzer davranış örüntüsü gösteren öğrenci gruplarının belirlenmesi mümkün 
olabilmektedir. Eğitimsel veri madenciliği, öğrencilerin bilgi düzeylerinin, tecrübelerinin modellenmesi aşamasında da uygulanarak uyarlanabilir ortamlar için gerekli olan bilginin toplanmasında da kullanılabilmektedir (Bienkowski, Feng ve Means, 2012).

Öğrenen profilinin çıkarılarak modellenmesi, gruplandırılması için veri madenciliği yöntemlerinden kümeleme analizi kullanılabilir. Kümeleme analizinde amaç benzer özellikler gösteren verileri homojen alt guruplara ayırmaktır. Alan yazında kümeleme analizi kullanılarak sanal öğrenme ortamlarında farklı öğrenci guruplarının davranışlarını belirleyen çalışmalar mevcuttur.

Cerezo ve ark.(2015), EM kümeleme ve k-ortalamalar (k-means) metodu kullanarak öğrencilerin Moodle log verilerine göre moodle aktivitelerini kullanmaları ile başarıları arasındaki ilişkiyi belirlemişlerdir.

Sael ve ark. (2013), Moodle daki eğitim ortamında harcanan toplam süre, her birimde geçirilen süre, forum gönderilerindeki kelime sayısı ve öğrenme ortamındaki etkinlik sayısına ait log verilerini kullanarak farklı öğrenci profillerini k-ortalamalar (k-means) kümeleme yöntemi ile belirlemişlerdir.

Saenz ve ark. (2011) öğrenen bağlılığı modellerini belirlemek için küme sayısını belirlemede k-ortalamalar (k-means) kümeleme algoritması kullanılmıştır. Çalışmanın sonuçlarına göre, destek hizmetleri kullanımı öğrenen grupları arasındaki benzerlik ve farklılıklarına yönelik en ayırt edici özellik olarak ortaya çıkmıştır.

Cristóbal Romero ve ark. (2008) öğrenci profillerinin belirlenmesinde moodle log verilerini kullanmış ve k-ortalamalar (k-means) kümeleme yönteminden yararlanmışlardır. Elde edilen bulgulara göre öğrencilerin sınıflandırılabileceğini ve işbirlikli çalışma grupları oluşturulabilineceğini vurgulamışlardır.

\section{Problemin Tanımı ve Önemi}

Alan yazında sanal öğrenme ortamlarının kullanım kolaylıkları, farklı sanal öğrenme ortamlarının karşılaştırılması, ortamların özellikleri, uzaktan eğitimde kullanımlarına yönelik çeşitli çalışmalar mevcuttur (Ergül, 2013; Floyd ve ark.,2012; Reis ve ark., 2012; Lonn ve ark., 2011). Ancak eğitim alanında veri madenciliği tekniklerinin kullanıldığı ve verilerin analiz edilerek sanal öğrenme ortamları üzerinde öğrenci hareketliliğinin incelendiği çalışmaların henüz yeterli düzeyde olmadığı görülmektedir (San Diego ve ark., 2012; Whitmer ve ark., 2012). Kümeleme algoritmaları yapılan çalışmalarda da tüm durumlarda kullanılabilecek tek bir modelin üretilmesinin mümkün olmadığı, sonuçların kullanılan 
YYÜ Ĕ̆itim Fakültesi Dergisi (YYU Journal of Education Faculty), 2019; 16(1):725-743, http://efdergi.yyu.edu.tr

değişkenlere göre farklılık gösterdiği belirtilmektedir (Romero ve Ventura, 2013; Gašević ve ark., 2016).

$\mathrm{Bu}$ araştırmada mevcut bütün avantajlarına rağmen sanal öğrenme ortamlarının öğretim kurumlarında yeterince etkin bir şekilde kullanılmamasının nedenleri, moodle sanal öğrenme ortamını kullanan öğrencilerin ortamı kullanırken sergiledikleri davranışlar incelenerek ele alınmıştır. Araştırmanın k-ortalamalar küme algoritması, memnuniyet, bilgisayar kaygısı ve yıl sonu akademik başarısı olmak üzere söz konusu birden fazla değişkene göre öğrenci davranışlarının dağılımlarının ve sanal öğrenme ortamlarındaki aktiviteler ile aralarındaki ilişkinin incelendiği ilk çalışma olması açısından alan yazına katkı sunması beklenmektedir.

Elde edilen bulguların sanal öğrenme ortamlarının veri madenciliği teknikleriyle değerlendirilerek eğitime destek amaçlı daha etkin kullanılmasına katkı sağlayacağı düşünülmektedir. Bu araştırma ile veri madenciliği tekniklerinin eğitim alanında kullanılması konusunda çalışmalar yapmak isteyen, benzer ya da farklı değişkenleri kullanarak sanal öğrenme ortamlarında öğrenci davranışlarını incelemek isteyen araştırmacılara katkı sağlanması amaçlamaktadır.

\section{Amaç}

$\mathrm{Bu}$ araştırmanın amacı; veri madenciliği tekniklerinden kümeleme algoritmaları yöntemi ile üniversite düzeyindeki öğrencilerin, sanal öğrenme ortamlarına yönelik memnuniyetleri, bilgisayar kaygıları, yıl sonu akademik başarılarına göre nasıl bir dağılım gösterdiğini belirlemek ve bu dağglıma göre Moodle sanal öğrenme ortamındaki aktivite kullanımları arasında farklılık olup olmadığını değerlendirmektir.

$\mathrm{Bu}$ amaç doğrultusunda aşağıdaki sorulara yanıt aranmıştır:

1. Sanal öğrenme ortamına yönelik memnuniyet, bilgisayar kaygısı ve yılsonu akademik başarı değişkenleri göz önüne alındığında benzer davranışı gösteren öğrenciler uygulanan kümeleme algoritmasına göre nasıl bir dağılım göstermektedir?

2. Bu dağılıma göre hangi gruptaki öğrenciler Moodle sanal öğrenme ortamına ait aktivitelerden hangilerini daha az, hangilerini daha fazla kullanılmışlardır?

\section{Yöntem}

$\mathrm{Bu}$ araştırma tarama modellerinden ilişkisel tarama modeline uygun olarak düzenlenmiş betimsel ve nicel bir çalışmadır. Tarama modelleri, geçmişte ya da halen varolan bir durumu varolduğu şekliyle betimlemeyi amaçlayan araştırma yaklaşımlarıdır. İlişkisel 
YYÜ Ĕ̆itim Fakültesi Dergisi (YYU Journal of Education Faculty), 2019; 16(1):725-743, http://efdergi.yyu.edu.tr

tarama modelleri, iki ve daha çok sayıdaki değişken arasında birlikte değişim varlığını ve/veya derecesini belirlemeyi amaçlayan araştırma modelleri olarak ifade edilmektedir (Karasar, 2012). Araştırmanın analizinde eğitimde veri madenciliği süreci izlenmiştir. Eğitimde veri madenciliği süreci, eğitsel sistemlerden elde edilen ham verinin, eğitimcilerin ve araştırmacıların kullanabileceği bilgiye çevirme süreci olarak tanımlanmaktadır (Garcia, Romero, Venture ve de Castro, 2011).

\section{Katılımcılar}

Araştırma 2017-2018 eğitim ve öğretim yılı bahar döneminde Ankara'da özel bir üniversitenin Fen ve Edebiyat Fakültesi'ne bağlı bölümlerinde okuyan CMPE 105- Bilgisayara ve Bilgi Sistemlerine Giriş dersine kayıtlı 1. sınıf öğrencileri ile gerçekleştirilmiştir. Örneklemi oluşturan toplam 131 öğrencinin demografik özellikleri ile ilgili tanımlayıcı istatistikler Tablo 1 'de yer almaktadır.

Tablo 1. Öğrencilerin özellikleri

\begin{tabular}{lcr}
\hline Cinsiyet & f & \% \\
\hline Kiz & 79 & 60.3 \\
Erkek & 52 & 39.7 \\
Toplam & 131 & 100.0 \\
\hline
\end{tabular}

Tablo 1'de görüldüğü gibi araştırmaya katılan öğrencilerin \%60.3'ü kız, \%39.7 si erkek öğrencilerdir.

\section{Araştırma Süreci ve Veri Toplama Araçları}

Araştırma problemi doğrultusunda öğrencilerin 2017-2018 eğitim öğretim yılı bahar dönemi Bilgisayara ve Bilgi Sistemlerine Giriş dersine ait memnuniyet anketi sonuçları, bilgisayar kaygısı anketi sonuçları, yıl sonu akademik başarı notları ve öğrencilerin Moodle üzerindeki hareketliliklerine ait log kayıtları olmak üzere dört farklı veri kaynağı kullanılmıştır. Ders 14 haftalık öğretim dönemi süresince tüm öğrencilere haftada 1 saat yüzyüze geri kalanı çevirimiçi olacak şekilde harmanlanmış (blended) olarak verilmiştir.

Memnuniyet Anketi: Bu çalışmada öğrencilerin dönem boyunca harmanlanmış olarak almış oldukları eğitime ilişkin memnuniyet düzeylerini belirlemede kullanmak üzere; Eryılmaz (2011) tarafından geliştirilmiş olan Çevirimiçi Ortamlara Yönelik Doyum Ölçeği-ÇDÖ kullanılmıştır. Ölçeğin Cronbah Alpha güvenirlik katsayısı 96 olarak belirlenmiştir. Ölçekte gerçekleştirilen dersin içeriği, tasarımı, öğretim üyesi, öğrenci beklentisi ve etkileşimi değerlendirmeye yönelik maddeler birinci faktör, sistemin bağlantı hızı ve teknik olarak 
YYÜ Eğitim Fakültesi Dergisi (YYU Journal of Education Faculty), 2019; 16(1):725-743, http://efdergi.yyu.edu.tr

değerlendirilmesine yönelik maddeler ikinci faktör olarak ele alınmıştır. ÇDÖ öğrencilere 14 haftalık sürecin sonunda uygulanmıştır. Alınan puanlar 100 üzerinden değerlendirilmiştir.

Bilgisayar Kaygısı Anketi: Araştırmada Saade ve Kira (2009) tarafından geliştirilen ve güvenilirliği Cronbach's alpha .79 olarak hesaplanan Bilgisayar Kaygısı Anketi kullanılmıştır. Anketteki maddeler Kesinlikle katılmıyorum ve Kesinlikle katılıyorum gibi ifadeleri içeren beşli Likert tipten oluşmaktadır. Ankette belirlenen sorulara göre öğrencilere kullanmış oldukları sanal öğrenme ortamında bulunan öğrenme araçlarını güvenli kullanımları ve verilen görevi tamamlamaları hakkındaki görüşlerinin belirlenmesi amaçlanmıştır. Anket öğrencilere 14 haftalık öğrenim sürecinin başında uygulanmıştır.

Yıl Sonu Akademik Başarı Notları: 14 haftalık sürecin sonucunda öğrencilerin birinci ara sınav, ikinci ara sınav ve final sınavı ortalamaları alınarak yıl sonu başarı notları belirlenmiştir. Yıl sonu başarı notları belirlenirken ara sınavların \%25'i ve Final sınavının \%50’si alınarak hesaplanmıştır. Tüm notlar 100 üzerinden değerlendirilmiştir.

Ayrıca öğrencilerin çalışma ortamındaki hareketliliğine (ders izlenceleri, aktiviteler, mesajlaşma, sisteme giriş v.b) Moodle sanal öğrenme ortamından ulaşılmıştır.

\section{Verilerin Çözümlenmesi}

Verilerin çözümlenmesi aşamasında öğrencilerin doyumları, bilgisayar kaygıları ve akademik başarıları, kümeleme algoritmalarından k-ortalamalar algoritması kullanılarak gruplandırılmıştır. Araştırmada elde edilen veriler SPSS Statistics 24.0 (The Statistical Package for The Social Sciences) istatistik programı kullanılarak çözümlenmiştir. İkinci araştırma sorusu kapsamında öğrencilerin Moodle sanal öğrenme ortamındaki hareketlilikleri ve bu hareketlerin öğrenci bazında dağılımları geleneksel istatistiksel yöntemler kullanılarak incelenmiştir. Verilerin çözümlenmesinde \%, aritmetik ortalama ve standart sapma gibi betimsel istatistikler de kullanılmıştır.

\section{Bulgular}

Araştırmanın bağımlı değişkenleri olan memnuniyet, kaygı ve yılsonu başarı puanlarına ait betimsel istatistikler Tablo 2' de verilmiştir.

Tablo 2. Araştırmanın Bağımlı Değişkenlerine İlişkin Betimsel İstatistikler

\begin{tabular}{lccccc}
\hline & N & En düşük & En yüksek & Ortalama & Std. sapma \\
\hline Memnuniyet & 131 & 10,00 & 100,00 & 62,9160 & 16,18168 \\
Kayg1 & 131 & 12,00 & 100,00 & 70,4275 & 19,37764 \\
SNot & 131 & 13,00 & 92,00 & 68,3588 & 14,27203 \\
N & 131 & & & & \\
\hline
\end{tabular}


YYÜ Eğitim Fakültesi Dergisi (YYU Journal of Education Faculty), 2019; 16(1):725-743, http://efdergi.yyu.edu.tr

Tablo 2 incelendiğinde öğrencilerin kaygı düzeylerinin ortalama olarak doyum ve akademik başarı ortalamalarından biraz daha yüksek olduğunu, doyum ortalamalarının $(\mathrm{X}=62.9)$ başarı ortalamalarından $(\mathrm{X}=68.3)$ biraz daha düşük olduğu görülmektedir.

Tablo 3. Bağımlı Değişkenlerin Kümelere Göre Dağ̊lımı

\begin{tabular}{lccc}
\hline & \multicolumn{3}{c}{ Küme(Cluster) } \\
\cline { 2 - 4 } & 1 & 2 & 3 \\
\hline Memnuniyet ( Zscore) &,- 52782 &, 68883 &,- 98684 \\
Kayg1 (Zscore) &,- 06507 &, 59479 & $-1,83913$ \\
SNot (Zscore) &,- 27650 &, 68101 & $-1,59538$ \\
\hline
\end{tabular}

Tablo 3'te belirtildiği gibi k-ortalamalar (k-means) kullanılarak yapılan analiz sonucunda öğrencilerin memnuniyet, kaygı ve akademik başarı puanlarına göre 3 gruba ayrilabilecekleri görülmüştür.

Çizelge 1. Kümeleme dağılımının grafiksel gösterimi

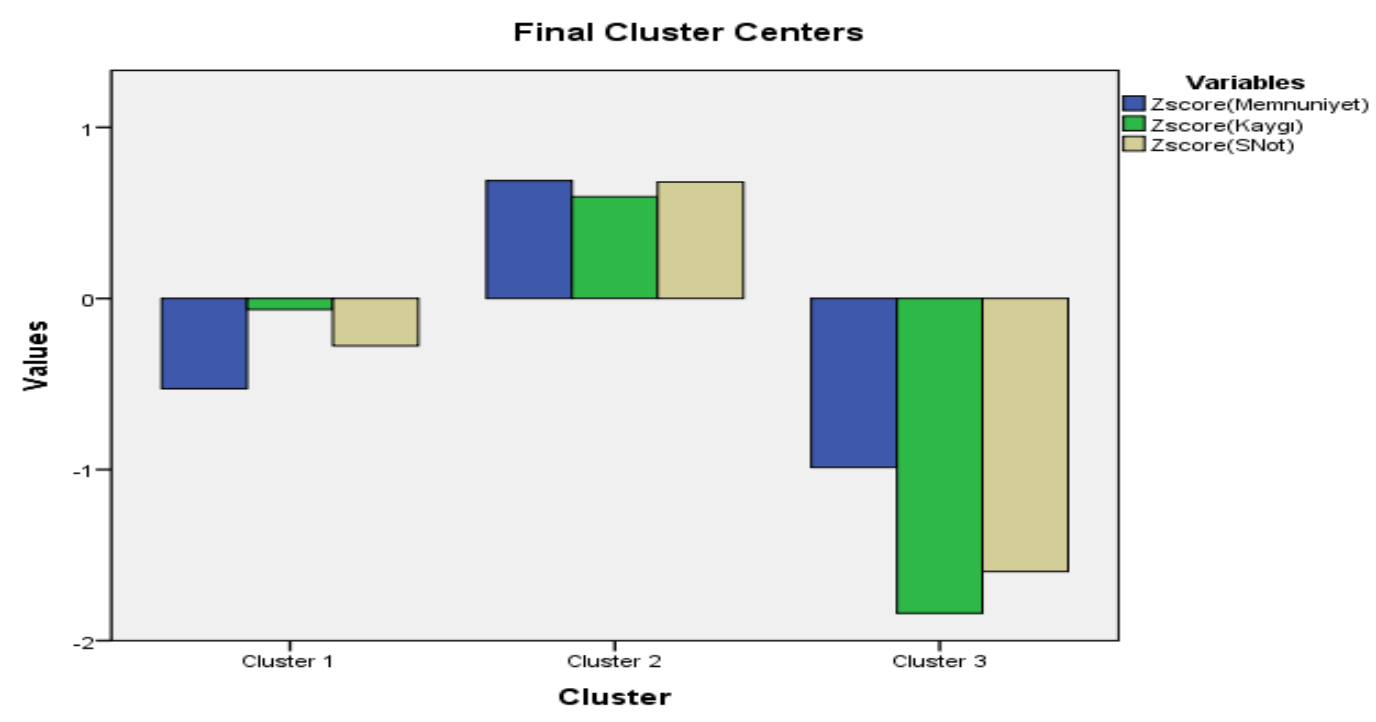

Tablo 3 ve Çizelge 1 incelendiğinde, orta düzey olarak ifade edilen küme 1 deki öğrencilerin doyum ve başarı düzeylerinin düşük, kaygı düzeylerinin sınıra yakın olduğu, yüksek düzey olarak ifade edilen küme 2 deki öğrencilerin kaygı düzeyleri yüksek olmasına rağmen memnuniyet ve başarı düzeylerinin de yüksek, düşük düzey olarak ifade edilen küme 3 teki öğrencilerin ise kaygı düzeyleri, akademik başarı ve memnuniyet düzeylerinin oldukça düşük olduğu görülmektedir. 
YYÜ Ĕ̆itim Fakültesi Dergisi (YYU Journal of Education Faculty), 2019; 16(1):725-743, http://efdergi.yyu.edu.tr

Tablo 4. Bağımlı değişkenlerin ANOVA sonuçları

\begin{tabular}{|c|c|c|c|c|c|c|}
\hline & \multicolumn{3}{|c|}{$\begin{array}{l}\text { Küme } \\
\text { (Cluster) }\end{array}$} & \multirow{2}{*}{$\begin{array}{l}\text { Hata } \\
\text { df }\end{array}$} & \multirow[b]{2}{*}{$\mathrm{F}$} & \multirow[b]{2}{*}{ Sig. } \\
\hline & $\begin{array}{l}\text { Kareler } \\
\text { Ortalamas1 }\end{array}$ & df & $\begin{array}{l}\text { Kareler } \\
\text { Ortalamas1 }\end{array}$ & & & \\
\hline Memnuniyet & 31,122 & 2 & ,529 & 128 & 58,792 & ,000 \\
\hline Kayg1 & 43,555 & 2 & ,335 & 128 & 129,987 & ,000 \\
\hline SNot & 40,855 & 2 & 377 & 128 & 108,294 & ,000 \\
\hline
\end{tabular}

Tablo 4 incelendiğinde yapılan ANOVAanalizi sonrasında değişkenlerden 3’ünün de seçilen kümeleme programı üzerinde anlamlı bir etkiye sahip olduğu görülmektedir $(p<.05)$.

Tablo 5. Öğrenci sayılarının kümelere göre dağılımı

\begin{tabular}{rrr}
\hline & Küme & N \\
\hline & 1 & 48 \\
& 2 & 64 \\
Toplam & 19 \\
Hata & 3 & 131 \\
\hline
\end{tabular}

Tablo 5 incelendiğinde analiz sonucuna göre en yüksek sayıda öğrenci 2. kümede (n=64) toplanmış, onu 48 öğrenci ile 1. küme ve 19 öğrenci sayısı ile 3. küme takip etmiştir. Öğrencilerin kümelere göre akademik başarılarına bakıldığında not ortalamalarının 1. küme için $X=64.4$, 2.küme için $X=78.07$ ve 3.küme için $X=45.6$ olduğu görülmektedir. $B u$ durumda en yüksek akademik başarıya sahip öğrenciler 2. kümedeki (yükssek düzey) öğrencilerdir.

Tablo 6. K-ortalamalar algoritmasına göre öğrencilerin moodle eylemlerinin küme ortalamaları

\begin{tabular}{llcr}
\hline Eylem & Küme1 (Orta) & Küme2(Yüksek) & Küme3(Düşük) \\
\hline Mesaj & 47,22 & 89,24 & 2,54 \\
Etiket & 28,44 & 59,74 & 0,04 \\
Cevap Okuma & 12,49 & 48,74 & 2,45 \\
Oturum & 48,77 & 85,47 & 21,11 \\
Mesaj Okuma & 54,14 & 91,51 & 8,11 \\
Gezinim_Kaynaklar & 35,47 & 72,11 & 0,54 \\
Gezinim_Duyurular & 47,13 & 91,14 & 17,14 \\
Tartı̧ma & 18,15 & 79,15 & 0,94 \\
Yorum & 59,14 & 75,66 & 0,72 \\
Soru Değerlendirme & 33,24 & 49,48 & 3,56 \\
Doküman paylaşımı & 32,33 & 67,24 & 15,12 \\
\hline
\end{tabular}


YYÜ Eğitim Fakültesi Dergisi (YYU Journal of Education Faculty), 2019; 16(1):725-743, http://efdergi.yyu.edu.tr

Tablo 6 incelendiğinde ikinci aşamada öğrencilerin moodle üzerindeki hareketliliği incelenerek öğrenciler tarafından gerçekleştirilen eylemlerin belirlenen kümelere göre nasıl bir dağılım gösterdiği incelenmiştir. Buna göre öğrencilerin moodle da kullanmış oldukları eylemler başlıklar halinde çıkarılmış ve sonrasında öğrenci kümelerinin bu başlıklara göre farklı davranış gösterip göstermediği belirlenmiştir.

Çizelge 2. Öğrencilerin Moodle eylemlerine ait grafik

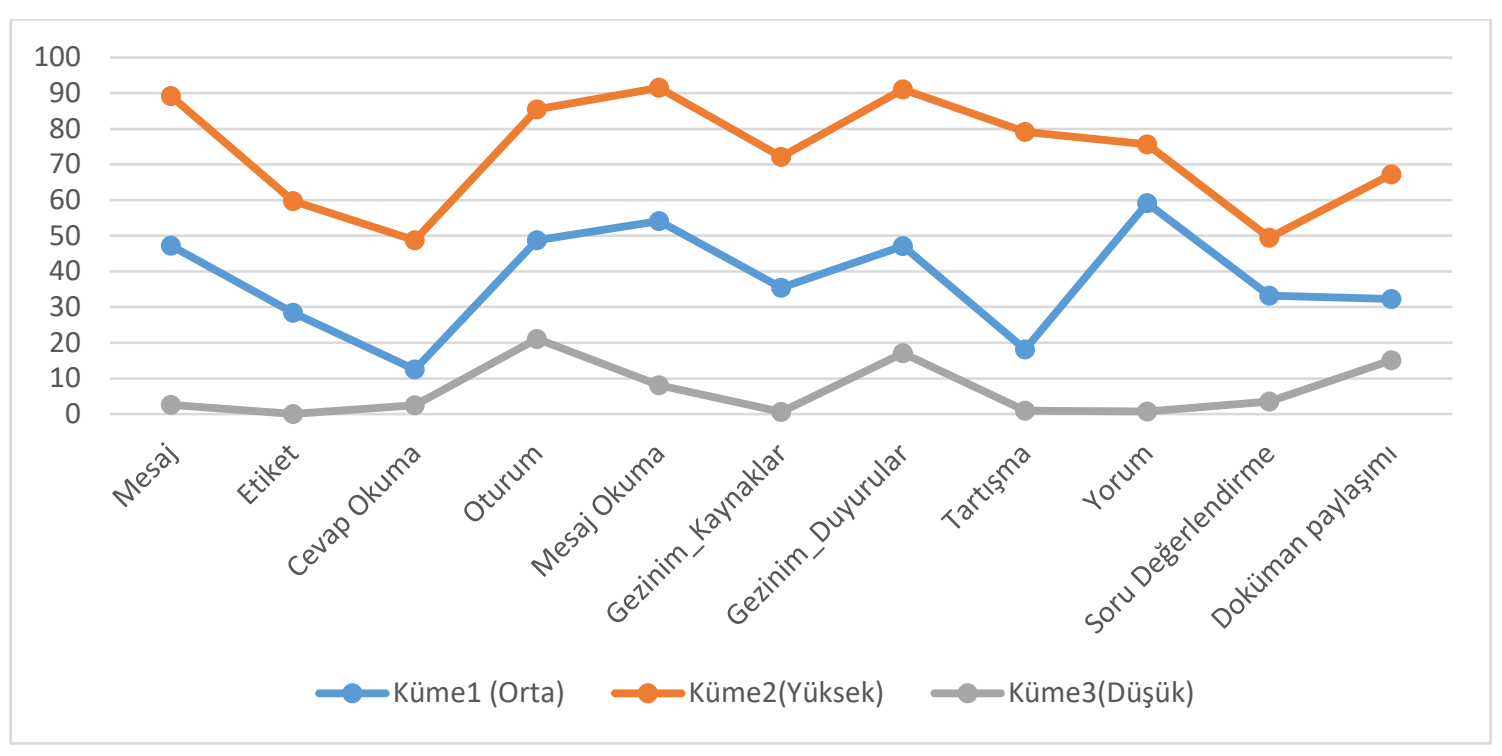

Çizelge 2 incelendiğinde elde edilen bulgular her üç küme için de moodle eylemlerinden cevapları okuma, kaynaklar arasında gezinim, tartışma platformunu kullanma ve soruları değerlendirme aktivitelerinin en düşük düzeyde kullanıldığını göstermektedir. Küme 3 (düşük düzey) teki öğrencilerin moodle eylemlerine genel olarak çok düşük düzeyde katıldıkları görülmektedir.

\section{Tartışma, Sonuç ve Öneriler}

Teknolojideki hızlı gelişmeler eğitim alanında da etkisini göstererek eğitim ve öğretim sürecinin gelişmesinde önemli rol oynamaktadır. Sanal öğrenme ortamlarının devreye girmesi ile geleneksel eğitim şekil değiştirmiş ve öğrencilerin zaman ve mekandan bağımsız olarak eğitim alması mümkün hale gelmiştir. Ayrıca bu ortamlar öğrenci etkinliklerini izleyebilme, kayıt edebilme ve öğrenci aktivitesi üzerine önemli miktarda veri toplayabilme özellikleri ile geleneksel eğitim ortamlarına göre daha gelişmiş olanaklara sahip hale gelmişlerdir. Sanal öğrenme ortamlarındaki öğrenci hareketlerinin kayıt altına alınabilmesi özelliği sayesinde, öğrenci verilerinin toplanıp analiz edilmesi geleneksel eğitim ortamlarına göre oldukça 
kolaydır. Veri madenciliği veri yığını içerisinde gizli kalmış anlamlı bilgilere ulaşmayı sağlayan bir süreç olarak ifade edilmektedir (Erten, 2015). Eğitimde kalite artışı, eğitimde yer alan öğrenci, öğretmen ve ders gibi öğelere yapılacak veri analizleri ile doğru orantılıdır (Ünal, 2014). Veri madenciliği yöntemlerinin eğitimde kullanılması özellikle büyük ölçekteki veriler için bu analizlerin daha etkili yapılabilmesi ve verimli sonuçlara ulaşılması sağlamaktadır (Bienkowski, Feng ve Means, 2012).

Sanal öğrenme ortamlarına yönelik memnuniyet, bilgisayar kaygısı ve yıl sonu akademik başarılarının nasıl bir dağılım gösterdiği araştırma sorularına göre değerlendirilmiştir. Buna göre birinci araştırma sorusu göz önüne alındığında, k-ortalamalar (k-means) kullanılarak yapılan analiz sonucunda öğrencilerin memnuniyet, kaygı ve akademik başarı puanlarına göre üç gruba ayrılabilecekleri görülmüştür. Bu gruplar orta, yüksek ve düşük düzey olarak tanımlanmıştır. Orta düzey olarak ifade edilen küme 1, memnuniyet ve başarı düzeyleri düşük, kaygı düzeyleri sınıra yakın öğrencilerden; yüksek düzey olarak ifade edilen küme 2, kaygı düzeyleri yüksek olmasına rağmen memnuniyet ve başarı düzeyleri de yüksek öğrencilerden; düşük düzey olarak ifade edilen küme 3 ise kaygı düzeyleri, akademik başarı ve memnuniyet düzeyleri oldukça düşük öğrencilerden oluşmaktadır. Bu kümeleme analizi sonucunda eğitim sürecinin başında yüksek kaygı düzeyine sahip olan öğrencilerin eğitim sürecinden olumlu yönde etkilenerek yüksek memnuniyet ve yüksek akademik başarıya sahip oldukları görülmektedir. Yapılan çalışmalar kaygının güdülenmeyi dolayısıyla öğrenmeyi olumsuz etkilediğini ve öğrencilerin zayıf akademik performans göstermelerine neden olabildiğini söylemektedir (McDonald, 2001; Cassady ve Johnson, 2002). Bu nedenle öğrenme ortamının öğrencilerin kaygı duymayacağı şekilde düzenlenmesinin oldukça önemli olduğu belirtilmektedir (Dilekmen ve Ada, 2005; Tanaka, Takehara ve Yamauchi, 2006). Bu çalışmada düzenlenen sanal öğrenme ortamının başarılı bir şekilde hazırlandığı ve deneysel süreç öncesinde yüksek kaygı düzeyinde olan öğrencilerin yüksek akademik performans göstermelerini sağladığı sonucuna varılabilir. Öğrencilerin memnuniyet puanlarının da yüksek olması bu sonucu doğruladığı söylenebilir.

Orta düzeydeki 1. kümedeki öğrencilerin eğitim süreci öncesinde kaygı düzeylerinin sınıra yakın olduğu, memnuniyet ve akademik başarılarının düşük ama kaygı düzeyleri çok düşük olan 3. kümedeki (düşük düzey) öğrencilerin memnuniyet ve akademik başarılarından daha yüksek olduğu görülmektedir. $\mathrm{Bu}$ durum, hazırlanan sanal öğrenme ortamında gerçekleştirilen eğitimin kaygıyı düşürerek akademik başarıyı ve memnuniyeti arttırdığı 
sonucunu destekler niteliktedir. 3. kümedeki öğrenci sayısı diğer iki kümeye göre daha azdır $(\mathrm{n}=19)$. Bu kümedeki öğrencilerin kaygı düzeyleri, memnuniyet ve akademik başarıları oldukça düşüktür. Bu sonuca göre, 3. kümedeki öğrencilerin genel olarak derse ve ortama ilgisiz olan öğrenciler olduğu düşünülmektedir.

İkinci araştırma sorusu göz önüne alındığında elde edilen bulgular her üç küme için de moodle eylemlerinden cevapları okuma, kaynaklar arasında gezinim, tartışma platformunu kullanma ve soruları değerlendirme aktivitelerinin en düşük düzeyde kullanıldığını göstermektedir. Düşük düzeydeki 3. kümedeki öğrencilerin moodle eylemlerine genel olarak çok düşük düzeyde katıldıkları görülmektedir. Bu öğrencilerin sadece oturum açarak duyurulara göz attıkları ve gerektikçe doküman paylaştıkları görülmektedir. Her üç grup için de düşük olan moodle eylemlerini geliştirmenin öğrencilerin memnuniyet ve akademik başarı puanları üzerinde etkili olacağı düşünülmektedir.

$\mathrm{Bu}$ çalışmanın bundan sonra özellikle eğitimsel veri madenciliği konusunda yapılacak çalışmalar için yol gösterici nitelikte olduğu düşünülmektedir. Farklı bağımlı değişkenler ile yapılacak yeni deneysel çalışmalar ile farklı sonuçlara ulaşılabilir. Sanal öğrenme ortamındaki öğrenci hareketleri, öğrencilerin aktivite kullanım tercihleri analiz edilerek sonraki eğitim uygulamaları için daha etkili ortamlar geliştirilebilir.

\section{Makalenin Bilimdeki Konumu}

Eğitim Bilimleri

\section{Makalenin Bilimdeki Özgünlüğü}

İlgili alan yazın göz önünde bulundurulduğunda veri madenciliği teknikleriyle sistem tarafından toplanan verilerin analiz edildiği, bu verilere dayanarak sanal öğrenme ortamları üzerindeki öğrenci hareketliliğinin incelendiği araştırmaların sayısal olarak azlığı dikkati çekmektedir (Leony ve ark., 2012; Whitmer ve ark., 2012; San Diego ve ark, 2012).

Araştırmada veri madenciliği algoritmalarından k-ortalamalar küme analizi, memnuniyet, bilgisayar kaygısı ve yıl sonu akademik başarısı olmak üzere birden fazla değişkene aynı anda uygulanmıştır. Bu araştırma Türkiye'de sanal öğrenme ortamlarında eğitimsel veri madenciliği kullanılarak söz konusu birden fazla değişkene göre öğrenci davranışlarının dağılımlarının ve sanal öğrenme ortamlarındaki aktiviteler ile aralarındaki ilişkinin incelendiği ilk çalışma olması açısından özgündür. 
YYÜ Eğitim Fakültesi Dergisi (YYU Journal of Education Faculty), 2019; 16(1):725-743, http://efdergi.yyu.edu.tr

\section{Kaynaklar}

Agnihotri, L. (2014). Building a student at-risk model: An end-to-end perspective. In Proc. 7th International Conference on Educational Data Mining.

Australian Flexible Learning Framework. (2007). Supporting e-learning Opportunities. Web sitesi: http://ldt.eworks.edu.au/

Bienkowski, M., Feng, M., \& Means, B. (2012). Enhancing teaching and learning through educational data mining and learning analytics: An issue brief. Washington, D.C. Web sitesi: https://www.researchgate.net/publication/320614434

Casey K. \& Gibson P.. (2010) (m)oodles of data: Mining moodle to understand student behaviour. In Proc. 3rd Irish Conference on Engaging Pedagogy.

Cassady, J. C., \& Johnson, R. E. (2002). Cognitive test anxiety and academic performance. Contemporary Educational Psychology, 27(2), 270-295.

Cerezo R., Sanchez-Santillan M., Nunez J.C., \& Paule M.P.(2015). Different patterns of students' interaction with moodle and their relationship with achievement. In Proc. 8th International Conference on Educational Data Mining.

Cristóbal, R., Sebastián, V., Mykola, P. \& Ryan, S. J. D. B. (2010). Introduction Handbook of Educational Data Mining (pp. 1-6): CRC Press.

Dilekman, M. ve Ada, Ş. (2005). Öğrenmede Güdülenme. Kazım Karabekir Eğitim Fakültesi Dergisi, 11, 113-123.

El-Deghaidy, H., \& Nouby, A. (2008). Effectiveness of a blended e-learning cooperative approach in an Egyptian teacher education programme. Computers \& Education, 51, 988-1006.

Ergül, E. (2013). Bilişim Teknolojileri Öğretmen Adaylarının Moodle İle Ders İşlenmesi Hakkındaki Görüşleri, Yüksek Lisans Tezi, Eğitim Teknolojileri Anabilim Dalı, Isparta.

Erten, H. (2015). Veri Madenciliği Teknikleri İle Organ Nakli İçin Uygun Donör Oranının Hesaplanması, Yüksek Lisans Tezi, Gazi Üniversitesi Fen Bilimleri Enstitüsü, Ankara.

Eryılmaz, M. (2011). Uyarlanabilir İçerik ve Uyarlanabilir Gezinmenin Öğrenci Doyumu ve Bilişsel Yüke Etkileri, Eğitim Bilimleri ve Uygulama Dergisi, 20.

Floyd, C., Schultz, T. \& Fulton, S. (2012). "Security Vulnerabilities in The Open Source Moodle E-learning System”, Proceedings of the 16th Colloquium for Information Systems Security Education, Lake Buena Vista, Florida, s. 42-47. 
YYÜ Eğitim Fakültesi Dergisi (YYU Journal of Education Faculty), 2019; 16(1):725-743, http://efdergi.yyu.edu.tr

Garnham, C. \& Kaleta, R. (2002). Introduction to Hybrid Courses. Teaching With Technology Today, 8 (6).

Gašević,D., Dawson, S.,Rogers,T.(2016). Learning analytics should not promote one sizefits all: The effects of instructional conditions in predicting academic success. The Internet and Higher Education, 28, 68-84.

Web sitesi : http://dx.doi.org/10.1016/j.iheduc.2015.10.002

García, E., Romero, C., Ventura, S. ve de Castro, C. (2011). A collaborative educational association rule mining tool. The Internet and Higher Education, 14(2), 77-88. doi: 10.1016/j.iheduc.2010.07.006

Greller,W. \& Drachsler,H.(2012). Translating Learning into Numbers: A Generic Framework for Learning Analytics. Educational Technology \& Society, 6(3),42-57.

Karasar, N. (2012). "Bilimsel Araştırma Yöntemi”, Nobel Yayın Dağıtım, 24. Baskı, s.76-81, Ankara.

Kışla T., Karaoğlan B., Bozok Algin G., Candemir C. (2014). Harmanlanmış Öğrenme Ortamında Moodle Platformunun Kullanılması Ile Ilgılı Paydaş Görüşlerının Incelenmesı, Ĕgitim ve Öğretim Araştırmaları Dergisi (Journal of Research in Education and Teaching), Cilt: 3 Sayı: 4 Makale No:15 sayfa: 154-167.

Lonn, S., Teasley, S.D. \& Krumm, A. E. (2011). Who Needs To Do What Where?: Using Learning Management Systems On Residential vs. Commuter Campuses, Computers \& Education, 56, 642-649.

Leony, D., Pardo, A., Valentin, L. F., Quinones, I. \& Kloos, C.D. (2012). Learning Analytics In The LMS: Using Browser Extensions To Embed Visualizations Into A Learning Management System, CEUR Workshop Proceedings, Web sitesi: http://ceurws.org/Vol894/paper6.pdf.

Mansouri, M. (2003). Perceptions of First -Time Participants in a StateAgency-Sponsored Online Graduate Program and Their Implications for Online Education Planning, Development and Support. VirginiaCommonwealth University School of Education. Unpublished Doctoral Dissertaiton.

Mcdonald, A. S. (2001) The Prevalence And Effects Of Test Anxiety İn School Children. Educational Psychology, An International Journal of Experimental Educational Psychology, 21 (1), 89-101. 
YYÜ Eğitim Fakültesi Dergisi (YYU Journal of Education Faculty), 2019; 16(1):725-743, http://efdergi.yyu.edu.tr

Murray, D. (2001). E-Learning for the Workplace. Creating Canada’s LifelongLearners. Web sitesi: http://en.copian.ca/library/research/cboc/aliant/aliant.pdf

Osguthorpe, R. T. \& Graham, C. R., (2003). Blended Learning Environments Definitions and Directions. The Quarterly Review of Distance Education, 4(3), 227-233.

Reis, A.Z., Baktır, H.Ö., Çelik, B., Erkoç, M.F., Özçakır, F.C., Özdemir, Ş. ve Şahin, K. (2012). Açık Kaynak Kodlu Öğrenme Yönetim Sistemleri Üzerine Bir Karşılaştırma Çalışması, Ĕ̈itim ve Öğretim Araştırmaları Dergisi, Cilt: 1, Sayı: 2, s. 42-58.

Romero,C., Espejo,P.G., Zafra,A., Romero, J. R. \& Ventura, S. (2013). Web usage mining for predicting final marks of students that use Moodle courses. Computer Applications in Engineering Education, 21(1), 135-146.

Romero,C.\& Ventura, S.,(2013).Data mining in education. Wiley InterdisciplinaryReviews:

Data Mining and Knowledge Discovery, 3(1), 12-27.

Saadé RG., \& Kira D.(2009). Computer anxiety in e-learning: The effect of computer selfefficacy. Journal of Information Technology Education 8.177-191.

Sael N., Marzak A. \& Behja H. (2013). Multilevel clustering and association rule mining for learners' profiles analysis. International Journal of Computer Science Issues (IJCSI), 10(3).

Saenz, V. B.; Kim, S.; Valdez, P.; Hatch, D.; Lee, K. ve Bukoski, B. E. (2011). Community college student engagement patterns: a typology revealed through exploratory cluster analysis. Community College Review, 39(3), 235-267.

San Diego, J.P., Ballard, J., Hatzipanagos, S., Webb, M., Khan, E., Blake, P., Dore, T., Konstantinidis, A., \& Barrett , I. (2012). Do Moodle analytics have a role to play in learning design, assessment and feedback?, 1 st Moodle ResearchConference, September, 14 - 15, Heraklion, Greece.

Semerci, A., ve Keser, H. (2013). E-öğrenme bariyerleri. Türkiye’de E-Öğrenme: Gelişmeler ve Uygulamalar, IV, Ocak 2013, Eskişehir, 105-123.

Siemens G. \& Long P. (2011). Penetrating the fog: Analytics in learning and education. EDUCAUSE Review 46 (5).

Tanaka, A., Takehara, T. \& Yamauchi, H. (2006). Achievement Goals İn A Presentation Task: Performance Expectancy, Achievement Goals, State Anxiety, And Task Performance, Learning and Individual Differences, 16, 93-99. 
YYÜ Eğitim Fakültesi Dergisi (YYU Journal of Education Faculty), 2019; 16(1):725-743, http://efdergi.yyu.edu.tr

Talavera, L.\& Gaudioso, E. (2004). Mining Student Data to Characterize Similar Behavior Groups in Unstructured Collaboration Spaces, 16th European Conference on Artificial Intelligence (ECAI 2004) - Workshop on Artificial Intelligence, 17-23, Valencia, Spain.

Ünal, T.A. (2014). Büyük Veri Ve Eğitimsel Veri Madenciliğinin Eğitim Alanına Katkılarının İncelenmesi, 8th International Computer \& Instructional Technologies Symposium, Trakya University Edirne.

Whitmer, J., Fernandes, K. \& Allen, W.R. (2012). Analytics in Progress: Technology Use, Student Characteristics, and Student Achievement, Educase, Web sitesi: http://www.educause.edu/ero/article/analytics-progress-technology-usestudentcharacteristics-and-student-achievement.

\section{Summary}

\section{Statement of Problem}

In the literature, there are various studies on the ease of use of virtual learning environments, comparison of different virtual learning environments, characteristics of environments, use of distance education. However, it is seen that data mining techniques are used in the field of education and studies on student mobility on virtual learning environments are analyzed the data, are not yet at a sufficient level. It is stated that it is not possible to produce a single model which can be used in all cases in clustering algorithms and the results differ according to the variables used. In this research, the behavior of students using moodle virtual learning environment while using the environment was investigated by considering the problem of using virtual learning environments in educational institutions in spite of all the existing advantages.In the study, k-means set algorithm was applied to multiple variables simultaneously, including satisfaction, computer anxiety and year-end academic success. For this reason, the study is unique in that it is the first study to examine the relationship between student behaviors according to these multiple variables and the activities in virtual learning environments. It is thought that the findings will contribute to the more effective use of virtual learning environments by using data mining techniques to support education. The aim of this research is to contribute to the researchers who want to study the use of data mining techniques in educational field and to investigate student behaviors in virtual learning environments by using similar or different variables. The purpose of this study is to determine how the university students' satisfaction, computer anxiety and year-end academic achievement levels are 
YYÜ Ĕ̆itim Fakültesi Dergisi (YYU Journal of Education Faculty), 2019; 16(1):725-743, http://efdergi.yyu.edu.tr

distributed in virtual learning environments by using clustering algorithm. At the same time, according to this distribution, it was evaluated whether there is any difference between the use of activities in Moodle virtual learning environment.

\section{Method}

The research was carried out with 131 first-year students studying in the departments of the Faculty of Arts and Sciences of Atılım University, Ankara in the spring term of 2017-2018 academic year. In line with the research problem, four different data sources were used: the results of the 2017-2018 academic year spring semester, satisfaction survey results, computer anxiety questionnaire results, year-end academic achievement grades and log records of students' activity on Moodle. During the course of application, students took the lesson as the combination of face to face and online. In this research, descriptive and quantitative study which is arranged in accordance with the relational screening model was followed as method and data mining process in education was used. At the stage of data analysis, students' satisfaction, computer anxiety and academic achievement were grouped by using K-means algorithm from clustering algorithms. The data obtained in this study were analyzed using SPSS Statistics 24.0 (Statistical Package for The Social Sciences). The mobility in Moodle virtual learning environment and student-based distribution of these movements were investigated using traditional statistical methods. Descriptive statistics such as \%, arithmetic mean and standard deviation were used in the analysis of the data.

\section{Findings}

According to the first research question is taken into consideration, it is seen that the results of the analysis using k-means can be divided into three groups according to the satisfaction, anxiety and academic achievement scores of the students. The groups are defined as Medium, High and Low levels. Cluster1, which is expressed as intermediate level, consists of students whose levels of satisfaction and achievement are low and anxiety levels are close to the limit. Cluster 2, which is expressed as a high level, consists of students with high levels of satisfaction and success even though the levels of anxiety are high. Cluster 3, which is expressed as low level, consists of students whose anxiety levels, academic achievement and satisfaction levels are very low. According to the second research question is taken into consideration, the findings show that the activities of reading the answers from moodle actions, using resources, using the discussion platform and evaluating the questions are used at the lowest level for all three sets. 
YYÜ Eğitim Fakültesi Dergisi (YYU Journal of Education Faculty), 2019; 16(1):725-743, http://efdergi.yyu.edu.tr

\section{Discussion and Conclusion}

As a result of the clustering analysis, it is observed that students who have high anxiety levels at the beginning of the education process have high satisfaction and high academic success by being affected positively from the education process. In this study, it can be concluded that the virtual learning environment prepared in this study has been successfully prepared and the students who have high anxiety level before the experimental process provide high academic performance. The high satisfaction level of the students confirms this result. The level of anxiety, satisfaction and academic achievement of the students in the third group are quite low. This result raises the idea that students in the 3rd group are students who are generally irrelevant to the course and the environment. According to the findings, it is thought that developing moodle actions for all three groups will have an effect on students' satisfaction and academic achievement points. This study is thought to be the guide for the studies on educational data mining. Different results can be achieved with new experimental studies with different dependent variables. Students' movements in the virtual learning environment can be analyzed by analyzing the activity usage preferences of the students and more effective environments can be developed for the subsequent training applications. 